\title{
Consideration for a role of videolaryngoscope in endotracheal intubation during continuous chest compression
}

\author{
Jun-ichi Koyama* \\ Neuroendovascular Therapy Center, Shinshu University Hospital, Japan
}

\section{Introduction}

With the introduction of new medical device, the treatment efficacy sometimes dramatically improves, and the new treatment method may become common. In the fields of acute ischemic stroke treatment, the effectiveness of recanalization therapy evolutionally improved by development of catheter instruments and its introduction [1]. As a result, catheter-based thrombectomy became the standard treatment instead of previous craniotomy-based thrombectomy surgery.

In the Recommendations of CoSTR 2017, chest compression should not be interrupted for ventilation as much as possible to improve the result of Cardio Pulmonary Resuscitation (CPR) [2]. So, it is required to achieve the endotracheal intubation without temporary cessation of chest compression. However, with using conventional Macintosh laryngoscope, endotracheal intubation is not easy to establish while continuing chest compression.

Reasons why endotracheal intubation during CPR is difficult are 1) the patient is placed in a lower position than usual, 2) various alien substances may exist in the oral cavity and airway of the patient, 3) the place for the assistant at endotracheal intubation is occupied by the person performing chest compression, 4) the patient's head is continuously moving about 100-120 times per minute.

Various videolaryngoscopes are expected as new devices to eliminate a difficult airway securing in the emergency situation. In the indirect viewing of the glottis with a monitor of the videolaryngoscope, it is not necessary to linearize the viewer's line of sight to the glottis as in the Macintosh laryngoscope. Therefore, high confirmability of the glottis in videolaryngoscope must work effectively to the inconvenience in positional relationship between the treatment person and the patient, which is liable to occur during chest compression [3].

Some videolaryngoscopes have a tube guiding function, and the intubation procedure becomes simpler by its function. As the intubation tube is attached to the guiding groove of the blade of videolaryngoscope in advance, observation of the glottis and taking a tube at the glottis can be done simultaneously without any assistant. Okada et al. reported that the guiding function made the success rate of the endotracheal intubation higher than guideless videolaryngoscope during continuing chest compression [4]. It can be understood that the more simplified procedure makes intubation procedure easier under patient's head movement.

Difficulty in observation when the lens becomes soiled with foreign matter is one of the common problems of the videolaryngoscopes. Existence of foreign substances in the oral cavity is obvious, the oral cavity should be cleared carefully with a suction device before attempt of endotracheal intubation.

In the first step of CPR, priority is given to chest compression, and then endotracheal intubation and subsequent oxygenation should be carried out as quickly as possible in an advanced medical environment, while continuing the chest compression. Particularly in CPR by an emergency medical rescuer outside the hospital, the endotracheal intubation should be established before transportation to a medical institution to conduct subsequent treatment more promptly. Clinical studies are awaited, that make what kind devices suit endotracheal intubation under chest compression be clear, and hopefully they will contribute the evolutional improvement in life-saving rate.

\section{Reference}

1. Goyal M, Menon BK, van Zwam WH, Dippel DW, Mitchell PJ (2016) Endovascular thrombectomy after large-vessel ischemic stroke: a meta-analysis of individual patient data from five randomized trials. Lancet 387: 1723-1731.

2. Olasveengen TM, de Caen AR, Mancini ME, Maconochie IK, Aickin R, et al. (2017) 2017 International Consensus on Cardiopulmonary Resuscitation and Emergency Cardiovascular Care Science with Treatment Recommendations Summary Resuscitation. Circulation 121: 201-214. [Crossref]

3. Koyama J, Iwashita T, Okamoto K (2010) Comparison of three types of laryngoscope for tracheal intubation during rhythmic chest compressions: a manikin study. Resuscitation 81: 1172-1174. [Crossref]

4. Okada D, Komasawa N, Fujiwara S, Minami T (2015) Comparison of tube-guided and guideless video laryngoscope for tracheal intubation during chest compression in a manikin: a randomized crossover trial. J Anesth 29: 331-337 [Crossref]
Copyright: (C)2018 Koyama J. This is an open-access article distributed under the terms of the Creative Commons Attribution License, which permits unrestricted use, distribution, and reproduction in any medium, provided the original author and source are credited.
${ }^{\star}$ Correspondence to: Jun-ichi Koyama, Chief Neuroendovascular Therapy Center, Shinshu University Hospital, 3-1-1 Asahi Matsumoto, 390-8621, Japan, Tel: 81-263-37-2690,E-mail: koyamaj@shinshu-u.ac.jp

Key words: video laryngoscope, endotracheal intubation, chest compression

Received: August 10, 2018; Accepted: August 25, 2018; Published: August 30, 2018 